\title{
Cross-Linked Chitosan Based Stomach Specific Mucoadhesive Microspheres Loaded with Amoxicillin: Preparation and ex vivo Characterization
}

\author{
Radha Rani Earle ${ }^{1, *}$, Vanthala Vijaya Bharathi ${ }^{1}$, Ayalasomayajula Lakshmi Usha', Andhavarapu Venkata Srinivasa Ksheera Bhavani ${ }^{2}$ \\ 'Department of Pharmaceutical Technology, Maharajah's College of Pharmacy, Vizianagaram, Andhra Pradesh, INDIA. \\ ${ }^{2}$ Department of Pharmaceutical Technology, Sri Venkateswara College of Pharmacy, Srikakulam, Andhra Pradesh, INDIA.
}

\begin{abstract}
Objectives: This research was aimed to evaluate a novel approach for preparation of mucoadhesive microspheres which can reside in the gastrointestinal tract for an extended time period. The microspheres contained amoxicillin, an anti-bacterial agent useful for the eradication of Helicobacter pylori. Methods: Ten different formulations were prepared by chemical cross-linking technique using gluteraldehyde as a cross linking agent and chitosan as mucoadhesive polymer. Natural release retardant polymers like guar gum, gum ghatti and xanthan gum were employed. All the microspheres were characterized for morphology, particle size, drug entrapment efficiency, swelling index, bioadhesion to mucosal tissue and in vitro drug dissolution and anti-bacterial activity against $E$. coli. Results: The FTIR and DSC data indicated that there were no interactions between the drug and polymers used. All the microspheres exhibited good flow properties. The microspheres had a spherical shape with rough surface. The microspheres showed a good mucoadhesivity and also anti-bacterial activity. The release
\end{abstract}

of the drug was prolonged to $12 \mathrm{~h}$ when incorporated into mucoadhesive microspheres. Conclusion: Data obtained in this study concluded that mucoadhesive microspheres of amoxicillin can be used to effectively clear $H$. pylori from the gastrointestinal tract due to prolonged residence time resulting from mucoadhesion. In this study drug release was diffusion controlled and followed zero order kinetics.

Key words: Glutaraldehyde, Helicobacter pylori, Zone of inhibition, Chick ileum, Mucoadhesion.

\section{Correspondence}

\section{Prof. Radha Rani Earle}

Assistant Professor, Department of Pharmaceutical Technology, Maharajah's College of Pharmacy, Vizianagaram, Andhra Pradesh, INDIA.

Phone no: +91-9963803008

Email: radhaearle@yahoo.com

DOI: 10.5530/ijpi.2020.1.11

\section{INTRODUCTION}

Mucoadhesion is an emerging concept which is used widely in most of the novel drug delivery systems via mucosal membrane of buccal, nasal, digestive tract, etc when administered through various routes. ${ }^{1}$ The mucoadhesive microspheres are used in sustained drug delivery with improved bioavailability and targeting efficacy due to their potential in localizing optimized drug delivery by retaining the formulation in contact with its site of absorption. ${ }^{2}$ The properties of mucoadhesive microspheres like their force of mucoadhesion, drug release pattern, surface characteristics and biodegradability are determined by the nature of the polymers used in their formulation. ${ }^{3}$

With the availability of variety of natural polymers, the manufacturers today have achieved a tremendous success in developing the most promising therapeutic systems i.e., drug delivery systems, that provide an effective therapy for prolonged time periods. ${ }^{4}$ Natural polymers are less expensive and are associated with minimum toxic effects when compared to synthetic release retardants. ${ }^{5}$ Chitosan is a biocompatible and biodegradable cationic polysaccharide which possesses mucoadhesive properties due to its ability to form strong interaction with the surface of mucosa. ${ }^{6}$

Amoxicillin is a semi-synthetic, broad spectrum antibiotic for oral use. Chemically it is $\alpha$-amino hydroxyl benzyl penicillin. ${ }^{7}$ Since decades it has been used for the standard treatment of gastric Helicobacter pylori eradication which is believed to be the major micro-organism responsible for the cause of gastric or peptic ulcers. Hence its eradication by enhancing the residence time of antibiotic in the stomach is a prerequisite for the treatment of gastric or peptic ulcer. ${ }^{8}$

The objective of this study was to formulate and evaluate in vitro and ex vivo performances of mucoadhesive amoxicillin microspheres for the potential use in the treatment of gastric and duodenal ulcers, which are associated with $H$. pylori using various natural release retardants. The physicochemical properties were examined using FTIR, DSC and XRD studies. The adhesion of microspheres to mucosal tissue (chick ilem) has been investigated. The antibacterial activity of the drug loaded microspheres was evaluated against a strain of $E$. coli.

\section{MATERIALS AND METHODS}

\section{Materials}

Amoxicillin, chitosan, guar gum, xanthan gum and ghatti gum were obtained from Yarrow Chem Products, Mumbai. Acetic acid was purchased from Finar Ltd., Light liquid paraffin, petroleum ether, Span 80; gluteraldehyde were obtained from Lotus enterprises.

\section{Preparation of microspheres by chemical cross-linking technique}

Amoxicillin loaded mucoadhesive microspheres were prepared by chemical cross-linking technique using gluteraldehyde as a cross linking agent. $4 \%$ chitosan solution (in acetic acid) was prepared and the required quantity of drug was dissolved in it. This solution was added 
drop wise into dispersion medium containing 25:35 v/v ratio of mineral oil+ petroleum ether and emulsifier. Dispersion medium was stirred with a mechanical stirrer at 1000-2000 rpm at room temperature. To this gluteraldehyde was added and the formed microspheres were collected. They were then washed with petroleum ether, sodium bisulfide and acetone. The microspheres were dried in an oven at $40^{\circ} \mathrm{C}$ for 2 days.

\section{Compatibility studies}

\section{FTIR analysis}

The FT-IR spectra of drug, polymers and crushed microspheres were scanned over a frequency range $4000-400 \mathrm{~cm}^{-1}$ by placing sample on diamond ATR and analyzing for the presence of characteristic peaks.

\section{Differential scanning Calorimetry}

The DSC analysis of pure drug, polymers and drug- loaded microspheres were carried out to evaluate any possible drug polymer interaction. The analysis was performed at a rate $10^{\circ} \mathrm{C} \mathrm{min}-1$ from $20^{\circ} \mathrm{C}$ to $30^{\circ} \mathrm{C}$ temperature range under nitrogen flow of $25 \mathrm{ml} \mathrm{min}^{-1}$.

\section{X-Ray powder diffractometry (X-RD)}

The X-ray diffraction patterns of pure drug and the crushed microspheres were recorded using Philips X-ray diffractometry (Ultima-III, Rigaku, Japan) with copper target to investigate the effect of microencapsulation on crystallinity of drug.

\section{Characterization of microspheres}

\section{Determination of micromeretic properties}

The microspheres were characterized by their bulk density, tapped density, compressibility index, Hausner's ratio and angle of repose. ${ }^{9}$

\section{Percentage Yield (\% yield)}

The percentage yield of microspheres was calculated as the weight of final product after drying to the initial weight of drug and polymer used for preparation of microspheres. ${ }^{10}$

Percentage yield $(\%)=\frac{\text { Weight of the microspheres }}{\text { Total weight of the drug and polymer taken }} \times 100$

\section{Estimation of drug entrapment efficiency}

A weighed quantity of microspheres (equivalent to $100 \mathrm{mg}$ of a drug) was crushed into powder and added to $100 \mathrm{~mL}$ of $0.1 \mathrm{~N} \mathrm{HCl}$ buffer. The resulting mixture was kept stirring at $2 \mathrm{hrs}$ and kept it overnight. Then the solution was filtered through the membrane whatman's filter and $1 \mathrm{~mL}$ of this solution was diluted using $0.1 \mathrm{~N} \mathrm{HCl}$ buffer and analyzed spectrophotometrically at $270 \mathrm{~nm}$ to get practical drug content. ${ }^{11}$

Drug entrapment efficiency $(\%)=\frac{\text { Practical drug content }}{\text { Theoretical drug content }} \times 100$

\section{Particle size analysis}

Particle Size of the microspheres was determined with the help of optical microscopy using stage micrometer and ocular micrometer. Microspheres were mounted on a glass slide and a minimum of 200 microspheres were counted per batch. ${ }^{12}$

\section{Shape and surface morphology}

The external morphology of the microspheres was analyzed using Scanning Electron Microscope (SEM). The microspheres were analyzed using a scanning electron microscope (JSM 6360, Joel make, UK). Samples were fixed on an aluminum stub with conductive double side adhesive tape.

\section{Equilibrium swelling studies}

Swelling index was determined by measuring the extent of swelling of microspheres in simulated gastric fluid. A known weight $(50 \mathrm{mg})$ of microspheres was allowed to swell in a glass vial containing $10 \mathrm{~mL}$ of $0.1 \mathrm{~N}$ $\mathrm{HCl}$ at $37 \pm 0.5^{\circ} \mathrm{C}$ for a period of $24 \mathrm{hr}$. The microspheres were periodically removed, blotted with filter paper and their changes in weights were measured during the swelling until equilibrium was attained. Finally, the weight of the swollen microspheres was recorded and the swelling ratio (SR) was then calculated from the formula. ${ }^{13}$

\section{Swelling index $(\mathrm{SI})=\mathrm{Wt} / \mathrm{Wo}^{*} 100$}

Where Wo = initial weight of microspheres and $\mathrm{Wt}=$ weight of microspheres at equilibrium swelling in the media.

\section{In vitro mucoadhesion test}

The mucoadhesive properties of the microspheres were evaluated by in vitro wash-off test. A $1 \times 1 \mathrm{~cm}$ piece of chicken stomach mucosa was mounted on to a glass slide with thread and rinsed with $0.1 \mathrm{~N} \mathrm{HCl}$. Microspheres were spread $(\sim 50)$ on a wet rinsed tissue specimen and the prepared slide was hung on to one of the grooves of a USP tablet disintegrating test apparatus which contained $900 \mathrm{~mL}$ of $0.1 \mathrm{~N} \mathrm{HCl}$ at $37 \pm 0.5^{\circ} \mathrm{C}$. When the disintegrating apparatus is operated, the tissue specimen is given slow regular up and down movement in the test fluid. At the end of $30 \mathrm{~min}, 1 \mathrm{hr}$ and at the hourly intervals up to $12 \mathrm{hr}$, the machine was stopped and number of microspheres still adhering to tissue was calculated. The studies were carried out in triplicate.

Percentage of Mucoadhesivenes $=\frac{\text { Number of microspheres adhered at the end of } 6 \mathrm{hr}}{\text { Number of microspheres spread }} \times 100$

\section{Antimicrobial studies}

The purpose of antibacterial studies was to find out drug release from formulations and its efficacy to inhibit the growth of micro-organisms. The antibacterial potency of the drug needs to be tested as the desired Minimum Inhibitory Concentration (MIC) has to be achieved. Antibacterial efficiency of amoxicillin-loaded mucoadhesive microspheres was assessed by determining MIC by standard tube dilution method against four standard pathogenic strains and was evaluated by performing the experiments in triplicate. Amoxicillin at different concentrations of $1-100 \mathrm{~g} / \mathrm{mL}$ in $\mathrm{HCl}(\mathrm{pH} 1.2)$ was tested against organism such as Escherichia coli (E. coli), For formulations F1 and F3, samples collected from in vitro release study of amoxicillin-loaded microsphere at different time intervals $(1,2,3,4,5,24 \mathrm{~h})$ were also tested against Escherichia coli.

\section{In vitro drug release studies}

Drug loaded mucoadhesive microspheres were carried out for $12 \mathrm{hrs}$ using paddle type dissolution apparatus (USP-XXIII Electrolab, Mumbai) containing $900 \mathrm{~mL}$ of dissolution apparatus at $37 \pm 0.5^{\circ} \mathrm{C}$ temperature and speed of agitation at $50 \mathrm{rpm}$. An accurately weighed quantity of microspheres was suspended in dissolution medium consisting 900 $\mathrm{mL}$ of gastric $(0.1 \mathrm{~N} \mathrm{HCl})$ fluid and the process were continued for up to $12 \mathrm{hrs}$.At present time intervals, $5 \mathrm{~mL}$ aliquots were withdrawn and replaced by an equal volume of fresh pre warmed dissolution medium. After suitable dilutions, the samples were analyzed spectrophotometrically at $270 \mathrm{~nm}$.

\section{Kinetic modeling}

Data obtained from dissolution studies was fitted to various kinetic equations. The kinetic models used were

zero order equation $\left(\mathrm{Q}_{\mathrm{t}}=\mathrm{Q}_{0}-\mathrm{k}_{\mathrm{o}} \mathrm{t}\right)$, 
First order equation $\left(\ln \mathrm{Q}_{\mathrm{t}}=\ln \mathrm{Q}_{0}-\mathrm{k}_{1} \mathrm{t}\right)$,

Higuchi's equation $\left(\mathrm{Q}_{\mathrm{t}}=\mathrm{k}_{\mathrm{HC}} \mathrm{t}_{1 / 2}\right)$,

Hixson-Crowell cube root law $\left(\mathrm{Q}_{0}{ }^{1 / 3}-\mathrm{Q}^{1 / 3}=\mathrm{k}_{\mathrm{HC}} \mathrm{t}\right)$,

Korsmeyer- Peppas equation $\left(\mathrm{M}_{\mathrm{t}} / \mathrm{M}_{\infty}=\mathrm{kt}^{\mathrm{n}}\right)$

The coefficient of regression and release rate constant values were computed to ascertain the mechanism of drug release. ${ }^{14}$

\section{RESULTS}

\section{Preparation of mucoadhesive microspheres}

Ten formulations of mucoadhesive micropsheres were prepared using different ratios of polymers like guar gum, xanthan gum, ghatti gum as shown in Table 1.

\section{Compatibility studies}

\section{FTIR analysis}

The IR spectrum of amoxicillin showed characteristic peaks corresponding to the functional groups present in the drug structure as shown in Figure 1. IR spectra of amoxicillin showed characteristic peaks at 1772.3 $\mathrm{cm}^{-1}$ (C=O of lactum ring), $1518 \mathrm{~cm}^{-1}$ (aromatic C-H), $2342.6 \mathrm{~cm}^{-1}(\mathrm{C}-\mathrm{N}$ bond), $1395.9 \mathrm{~cm}^{-1}$ (carboxylic acid), $3445.9 \mathrm{~cm}^{-1}$ (-OH group).

\section{Differential scanning Calorimetry}

The DSC thermogram of amoxicillin exhibited a sharp endothermic peak at $135.11^{\circ} \mathrm{C}$ corresponding to its melting point, indicating its crystalline nature. The onset of melting was obtained at $96.65^{\circ} \mathrm{C}$. The DSC
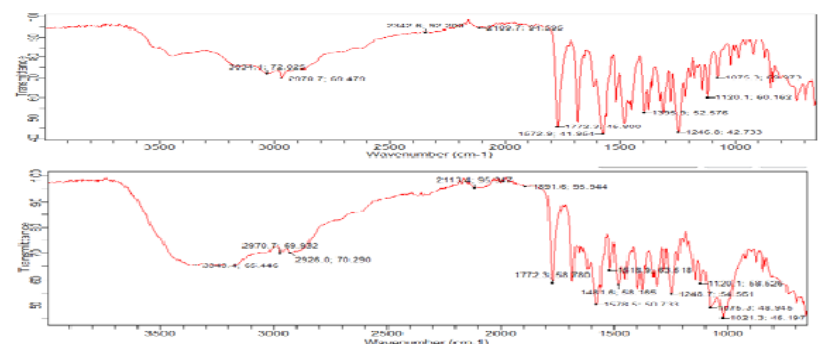

(B)

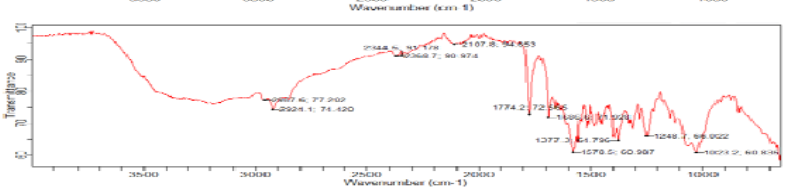

Figure 1: FTIR overlay spectrogram of (A) Amoxicillin; (B) physical mixture of microspheres; (C) crushed microspheres.

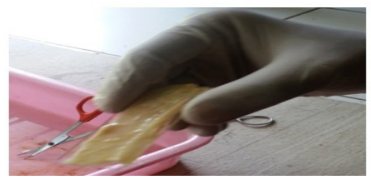

(A) Image of GI tissue for

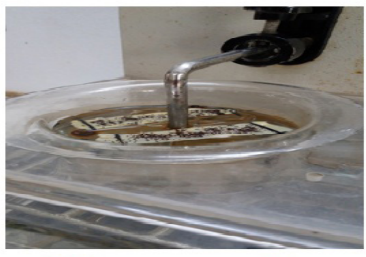

(C) Image on prepared microspheres on GI in mucoadhesion

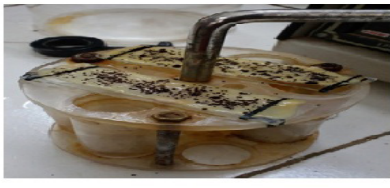

(B) Image of prepared microspheres on GI tissue

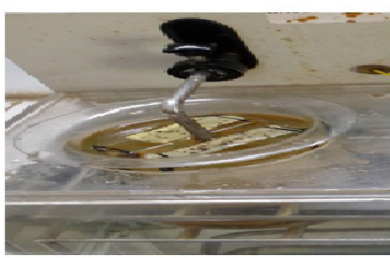
(D) Number of microspheres
adhered at the end of $\mathbf{8}$ hours
Figure 2: Test for mucoadhesion on chicken ileum.

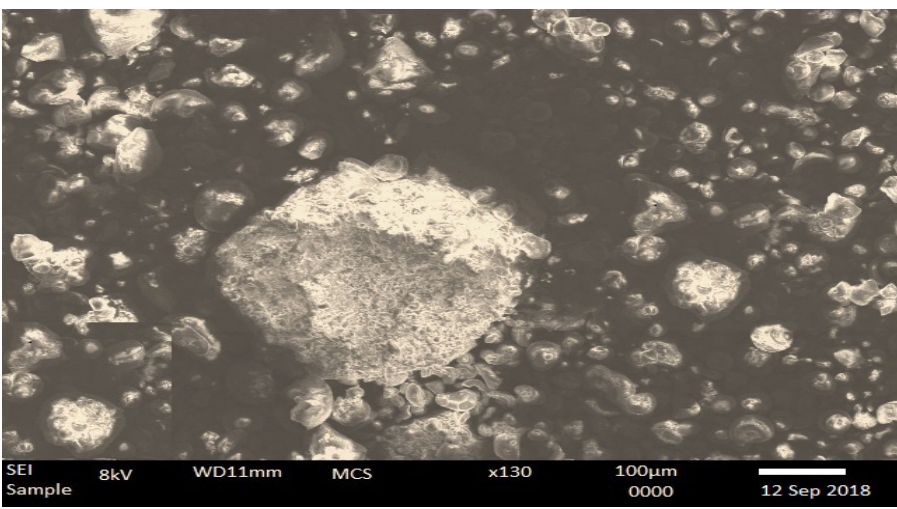

Figure 3: SEM image of mucoadhesive microsphere.

curves of chitosan and guar gum were obtained at $95.89^{\circ} \mathrm{C}$ and $167^{\circ} \mathrm{C}$ corresponding to their respective melting points.

\section{X-Ray diffractometry (X-RD)}

Amoxicillin exhibited a series of intense peaks at $16.219^{\circ}$ and $26.939^{\circ}$ which were indicative of its crystalline nature.

\section{(c) Characterization of microspheres}

\section{Determination of micromeretic properties}

Flow properties like angle of repose, bulk density, tapped density; Carr's index and Hausner's ratio of the drug were studied.

Table 1: Formulation of amoxicillin loaded microspheres.

\begin{tabular}{|c|c|c|c|c|c|c|c|c|c|c|}
\hline $\begin{array}{l}\text { Formulation } \\
\text { code }\end{array}$ & Drug (g) & $\begin{array}{l}\text { Chitosan } \\
\text { (g) }\end{array}$ & $\begin{array}{l}\text { Guar gum } \\
\text { (mg) }\end{array}$ & $\begin{array}{l}\text { Xanthan } \\
\text { gum }(\mathrm{mg})\end{array}$ & $\begin{array}{c}\text { Ghatti } \\
\text { gum }(\mathrm{mg})\end{array}$ & $\begin{array}{c}\text { Span } 80 \\
(\mathrm{~mL})\end{array}$ & $\begin{array}{l}\text { Gluteraldehyde } \\
(\mathrm{mL})\end{array}$ & $\begin{array}{c}\text { Acetic } \\
\text { acid (\%) }\end{array}$ & $\begin{array}{l}\text { Light Liquid } \\
\text { paraffin }(\mathrm{mL})\end{array}$ & $\begin{array}{l}\text { Petroleum } \\
\text { ether }(\mathrm{mL})\end{array}$ \\
\hline $\mathrm{F} 1$ & 1 & 1 & - & - & - & 2 & 2 & 5 & 25 & 35 \\
\hline F2 & 1 & 1 & 31.25 & - & - & 2 & 2 & 5 & 25 & 35 \\
\hline F3 & 1 & 1 & 62.5 & - & - & 2 & 2 & 5 & 25 & 35 \\
\hline $\mathrm{F} 4$ & 1 & 1 & 125 & - & - & 2 & 2 & 5 & 25 & 35 \\
\hline F5 & 1 & 1 & - & 31.25 & - & 2 & 2 & 5 & 25 & 35 \\
\hline F6 & 1 & 1 & - & 62.5 & - & 2 & 2 & 5 & 25 & 35 \\
\hline F7 & 1 & 1 & - & 125 & - & 2 & 2 & 5 & 25 & 35 \\
\hline F8 & 1 & 1 & - & - & 31.25 & 2 & 2 & 5 & 25 & 35 \\
\hline F9 & 1 & 1 & - & - & 62.5 & 2 & 2 & 5 & 25 & 35 \\
\hline F10 & 1 & 1 & - & - & 125 & 2 & 2 & 5 & 25 & 35 \\
\hline
\end{tabular}




\section{Percentage yield of microspheres}

Percentage yield of microspheres of different batches F1-F10 were found to be in the range of $83.94 \%$ to $94.80 \%$.

\section{Drug entrapment efficiency}

Entrapment efficiency of all the formulations ranged from $75.8 \%$ to $92.9 \%$.

\section{Particle size determination}

The average particle size range was $66.38 \mu \mathrm{m}$.

\section{Equilibrium swelling index (\%)}

Swelling index of the prepared microspheres was in the range of $91.5 \%$ to $118.7 \%$.

\section{Mucoadhesivity of microspheres (\%)}

Mucoadhesivity of the microspheres was found to be in the range of 86.32-77.21\% for F2-F4 formulations prepared with guar gum, 78.43$89.65 \%$ for F5-F7 formulations prepared with xanthan gum and 92.16$83.71 \%$ for formulations F8-F10 prepared with ghatti gum.

\section{Antibacterial studies}

Antibacterial activity of amoxicillin against E. coli showed the highest mean zone diameter of $1.5 \mathrm{~cm}$. The antibacterial activity of in vitro dissolution samples against $E$. coli were found to be $2.5 \mathrm{~cm}$.

\section{Surface morphology}

SEM photographs of optimized formulation of microspheres of amoxicillin showed that the microspheres were discrete spherical and uniform in shape as shown in Figure 3.

\section{In vitro drug release studies}

The cumulative in vitro release studies of different formulations of amoxicillin were performed in $0.1 \mathrm{~N} \mathrm{HCl}$ buffer for $12 \mathrm{hr}$. The samples were spectrophotometrically analyzed at $270 \mathrm{~nm}$. Formulation F1 showed $84.74 \%$ drug release respectively in $8 \mathrm{hr}$ without any sustained action. So, in order to sustain the drug release polymers like guar gum, xanthan gum, ghatti gum were utilized along with chitosan. In formulations F2, F3, F4, the drug release was found to be $98.23 \%, 99.73 \%, 80.96 \%$ respectively in 10, 12 and $12 \mathrm{hr}$. Formulations F5, F6, F7 showed drug release of $83.17 \%, 78.24 \%, 75.12 \%$ respectively in 12 hrs. Formulation F8, F9, F10 showed release of $96.32 \%, 98.74 \%, 83.16 \%$ respectively in 10,11 and $12 \mathrm{hr}$.

\section{Kinetics of drug release}

The in vitro dissolution data was fitted in different kinetic models like Zero order, First order, Higuchi, Korsemeyer-Peppas and Hixon Crowell equation.

\section{DISCUSSION}

Ten formulations of mucoadhesive micropsheres were prepared using different ratios of polymers like guar gum, xanthan gum, ghatti gum. Presence of any interaction between drug and polymers used often leads to significant changes in IR spectra of the drug-polymer mixture. Absence of significant shifting in intensity of peaks and band width showed that no incompatibilities occurred between the drug and polymers used. In the DSC curve of crushed microspheres, the original peaks were retained and no additional peaks were obtained. This indicated that amoxicillin and the polymers used are compatible with each other. The diffractogram of amoxicillin microspheres showed retention of original characteristic peaks which indicated physical compatibility between the drug and excipients.

All the microspheres have exhibited good flow property from micromeretic properties. They exhibited good entrapment efficiency and an equilibrium swelling index values. The SEM images indicated free flowing nature of the microspheres (Figure 2). It also showed that microspheres had a rough and porous outer surface.

The in vitro dissolution data indicated that all the formulations released the drug over a period of $12 \mathrm{hr}$. Comparing the correlation coefficient values of zero order (0.932) and first order (0.664), it was found that drug release follows zero order kinetics indicating that drug release was independent of concentration. In order to find out the release component $(n)$ value, the release data was analyzed as per Korsemeyer-Peppas model. The ' $n$ ' value of $F 3$ batch was found to be 0.827 ensuring that the drug release followed non- Fickian or anomalous diffusion mechanism. This type of release behaviours was generally exhibited by swelling controlled drug delivery systems where solvent up take determines the swelling rate of the polymer and drug release.

\section{CONCLUSION}

The designed formulation F3 adheres in the stomach and prolongs the gastric residence time (GRT) consequently, providing sustained action. From the results we can conclude that design of mucoadhesive microspheres employing natural gums by gluteraldehyde cross linking technique can be widely used to encapsulate wide range of drugs to achieve sustained drug delivery.

\section{ACKNOWLEDGEMENT}

The authors would like to thank Dr. P. Udaya Shankar, Principal, Maharajah's College of Pharmacy, Vizianagaram for providing required facilities to carry out this research work. We are also thankful to Dr. Ranjit Prasad Swain, Assistant Professor, Maharajah's College of Pharmacy, Vizianagaram for his support and encouragement during this work.

\section{CONFLICT OF INTEREST}

The authors declare no conflict of interest.

\section{ABBREVIATIONS}

FTIR: Fourier Transform Infrared Spectroscopy; HCl: Hydrochloric acid; E coli: Escherichia coli.

\section{REFERENCES}

1. Anupama S, Pramod KS, Rishabha M. Sustained drug delivery using mucoadhesive microspheres: the basic concept, preparation methods and recent patents. Recent Pat Nanomed. 2012;2(1):62-77.

2. Yunying $T$, Yifan $L$, Yinjing $S$, Bing G, Weiyue $L$, Jun P. Development of mucoadhesive microspheres of acyclovir with enhanced bioavailability. Int J Pharm. 2009;378(1-2):30-6.

3. Ofokansi KC, Adikwu MU, Okore VC. Preparation and evaluation of mucin-gelatin mucoadhesive microspheres for rectal delivery of ceftriaxone sodium. Drud Dev Ind Pharm. 2007;33(6):691-700.

4. Shanmugam S, Manavalan R, Venkappayya D, Sundaramoorthy K, Mounnissamy VM, Hemalatha S, et al. Natural polymers and their applications. Nat Prod Radiance. 2005;4(6):478-81.

5. Jayvadan KP, Jyant RC. Formulation and evaluation of stomach-specific amoxicillin-loaded carbopol-934P mucoadhesive microspheres for anti-Helicobacter pylori therapy. J Microencapsul. 2009;26(4):365-76.

6. Ping $\mathrm{H}$, Stanley SD, Lisbeth I. In vitro evaluation of the mucoadhesive properties of chitosan microspheres. Int J Pharm. 1998;166(1):75-68.

7. Zhepeng L, Weiyue L, Lisheng $Q$, Xuhui Z, Pengyun Z, Jun P. In vitro and in vivo studies on mucoadhesive microspheres of amoxicillin. J Control Release. 2005; 102(1):135-44

8. Myung KC, Hongkee S, Hoo KC. Preparation of mucoadhesive microspheres containing antimicrobial agents for eradication of $\mathrm{H}$. pylori. Int $\mathrm{J}$ Pharm. 2005;297(1-2):172-9. 
9. Nnabuike DN, Tochukwu JNO. Optimization of metronidazole tablet formulation using Manihot utilissima starch and a combination of processing techniques. Future J Pharm Sci. 2017;3(1):65-70.

10. Aashima H, Arun N, Manish J, Vikash K, Permender R. Optimization and evaluation of gastroretentive ranitidine $\mathrm{HCl}$ microspheres by using design expert software. Int J Biol Macromol. 2012;51(5):691-700.

11. Muniyandy S, Boddapati A. Development and evaluation of ethylcellulose floating microspheres loaded with ranitidine hydrochloride by novel solvent evaporation-matrix erosion method. Carbohydrate Polymers. 2011;85(3):592-8.
12. Rajkumar P, Ritesh SB, Deepak K, Sachin J. Formulation and evaluation of gastroretentive beads of Ranitidine hydrochloride. IJPPS. 2014;6(2):237-42.

13. Pund YP, Atish KSM. Design and development of sustained release floating beads of metronidazole using natural polymer. Sci Fed Drug Deli Res J. 2017;1:1-9.

14. Anjan KM, Narasimha MP, Radha RE, Pallavi SS, Ruchita KP. An updated review on technical advances to enhance dissolution rate of hydrophobic drugs. Int Res J Pharm. 2012;3(10):1-7.

Cite this article: Earle RR, Bharathi WV, Usha AL, Bhavani AVSK. Cross-Linked Chitosan Based Stomach Specific Mucoadhesive Microspheres Loaded with Amoxicillin: Preparation and ex vivo Characterization. Int. J. Pharm. Investigation. 2020;10(1):59-63. 